\title{
Impact of Mixed Convection on Ceiling Radiant Cooling Panel Capacity
}

\author{
Jae-Weon Jeong \\ Student Member ASHRAE
}

\author{
Stanley A. Mumma, Ph.D., P.E. \\ Fellow ASHRAE
}

The main thrust of the research described in this paper was to develop a simplified method of accurately estimating the impact of mixed convection on the cooling capacity of a ceiling radiant panel in mechanically ventilated spaces. The simplified correlation for mixed convection heat transfer was derived from established mixed and natural convection correlations. It was found that the total capacity of ceiling radiant cooling panels can be enhanced in mixed convection situations by $5 \%$ to $35 \%$ under normal operating temperatures.

\section{INTRODUCTION}

Currently, most ceiling radiant cooling panel (CRCP) performance estimates are based on natural convection only. This is reflected in ASHRAE (2000) literature, where the analysis is based upon the natural convection heat transfer work of Min et al. (1956), and the European CRCP capacity rating standard, DIN 4715 (1997), which uses natural convection as the test condition. However, Kochendörfer (1996) found that in real buildings, cooling outputs of CRCPs are significantly higher $(25 \%)$ than measured panel capacities tested in the laboratory under DIN 4715 conditions. In real buildings, mechanical ventilation systems are usually used, and the walls are not adiabatic. If the higher performance of CRCPs is ignored in the design phase, unnecessary panel area is specified and the cost of the panels is excessive.

\section{CONVECTION COEFFICIENT}

The two major sources of reliable building-related natural convection heat transfer coefficients are Awbi and Hatton (1999) and Min et al. (1956). The natural convection coefficient proposed by Min et al. is as follows:

$$
h_{c}=2.13 \cdot\left(T_{a}-T_{p m}\right)^{0.31}
$$

A number of works referenced in the literature that deal with mixed convection include Chen et al. (1989), Fisher and Pedersen (1997), and Awbi and Hatton (2000). Awbi and Hatton proposed mixed convection heat transfer coefficients for heated room surfaces partially covered by air jet. The correlation for a heated floor or cooled ceiling is as follows:

$$
h_{c}=\left(h_{c n}^{3.2}+h_{c f}^{3.2}\right)^{1 / 3.2}
$$

Jae-Weon Jeong is a doctoral student and Stanley A. Mumma is a professor in the Department of Architectural Engineering, The Pennsylvania State University, University Park, Pa.

(C) 2003 ASHRAE. This document is not to be distributed without written permission from ASHRAE. 
Table 1. Coefficients for Correction Function

\begin{tabular}{c|c|c|c|c}
\hline $\mathbf{a}_{\mathbf{1}}$ & $\mathbf{a}_{\mathbf{2}}$ & $\mathbf{a}_{\mathbf{3}}$ & $\mathbf{a}_{\mathbf{4}}$ & $\mathbf{a}_{\mathbf{5}}$ \\
\hline 0.12933333 & 1.294888889 & 0.051308333 & -0.29422 & 0.016286666 \\
\hline $\mathrm{a}_{6}$ & $\mathrm{a}_{7}$ & $\mathrm{a}_{8}$ & $\mathrm{a}_{9}$ & \\
\hline-0.049091666 & 0.00417 & 0.001202777 & -0.000111666 & \\
\hline \multicolumn{4}{c}{$h_{c n}$} & $=\frac{2.175}{D_{e}^{0.076}}\left(T_{a}-T_{p m}\right)^{0.308}$ \\
$h_{c f}$ & $=4.25 \cdot W^{0.575} \cdot V^{0.557}$ & (2b)
\end{tabular}

\section{SIMPLIFIED MIXED CONVECTION COEFFICIENT}

In this research, the mixed convection heat transfer coefficient developed by Awbi and Hatton (2000) was extensively analyzed to derive a simplified mixed convection coefficient that can be more easily used in the design stage of a CRCP system. Awbi and Hatton's mixed convection correlation for a cooled ceiling (Equation 2) is a function of the characteristic diameter of a space $\left(D_{e}\right)$, space-to-panel temperature difference $(\Delta T)$, diffuser width $(W)$, and diffuser discharge air velocity $(V)$.

Forced convection effects, the difference between natural convection coefficients and mixed convection coefficients, for various $\Delta T$ and $V$ values were calculated using Equations 1 and 2, respectively. Equation 3a returns the forced convection effect in $\mathrm{W} / \mathrm{m}^{2} \cdot \mathrm{K}$, whose required coefficients are presented in Table 1. The final form of the simplified mixed convection correlation, a result of adding the forced convection effect to the natural convection coefficient (Equation 1), is presented in Equation 3b.

$$
\begin{gathered}
f(V, \Delta T)=a_{1}+a_{2}(V)+a_{3}\left(V^{2}\right)+a_{4}(\Delta T)+a_{5}\left(\Delta T^{2}\right)+a_{6}(V \cdot \Delta T) \\
a_{7}\left(V^{2} \cdot \Delta T\right)+a_{8}\left(V \cdot \Delta T^{2}\right)+a_{9}\left(V^{2} \cdot \Delta T^{2}\right) \\
h_{c}=f(V, \Delta T)+2.13 \cdot \Delta T^{0.31}
\end{gathered}
$$

Convective heat transfer coefficients were computed for the space illustrated by Figure 1 using the simplified mixed convection equation as well as the equations of Chen et al. (1989), Fisher and Pedersen (1997), Min et al. (1956), and Awbi and Hatton (2000). The comparisons for various $\Delta T \mathrm{~s}$ and $V \mathrm{~s}$ are presented in Figure 2 and Figure 3, respectively. While not presented in those figures, it can be shown that the convection coefficients are insensitive to the space characteristic diameter $\left(D_{e}\right)$ and the diffuser width $(W)$.

\section{CEILING RADIANT COOLING PANEL MODEL}

The steady-state analytical CRCP model developed by Conroy and Mumma (2001) was used to estimate enhanced panel cooling capacity with mixed convection. The CRCP model is based on the landmark work of Hottel and Whillier (1958).

$$
\begin{gathered}
q_{o}=U_{o}\left(T_{a}-T_{p m}\right) \\
T_{p m}=T_{f i}+\frac{M C_{p}\left(T_{f o}-T_{f i}\right)}{A_{p} F_{R} U_{o}} \cdot\left(1-F_{R}\right)
\end{gathered}
$$




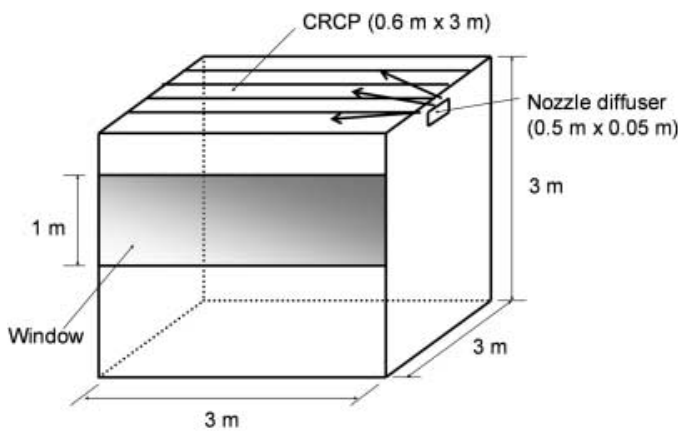

Figure 1. Schematic of Model Space

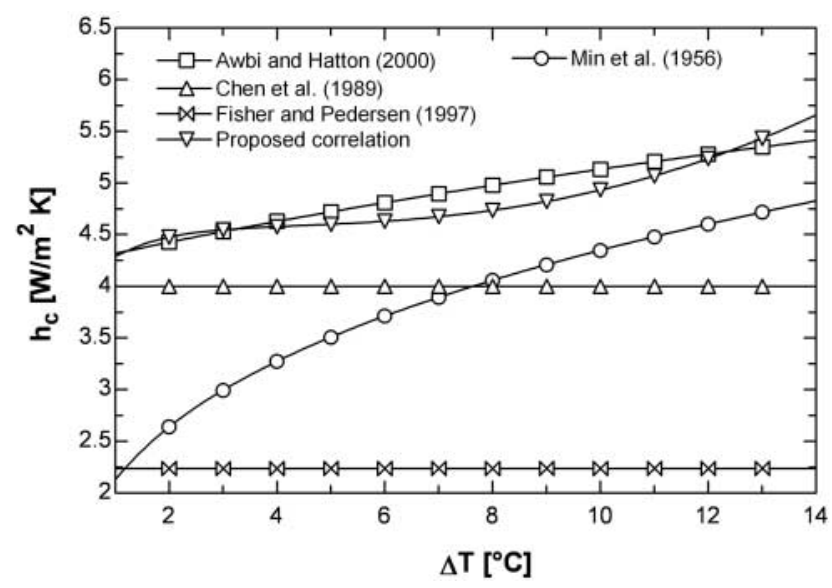

Figure 2. Mixed Convection Heat Transfer Coefficients for Various $\Delta T$ $\left(V=2 \mathrm{~m} / \mathrm{s}, D_{e}=3 \mathrm{~m}, V=0.5 \mathrm{~m}\right)$

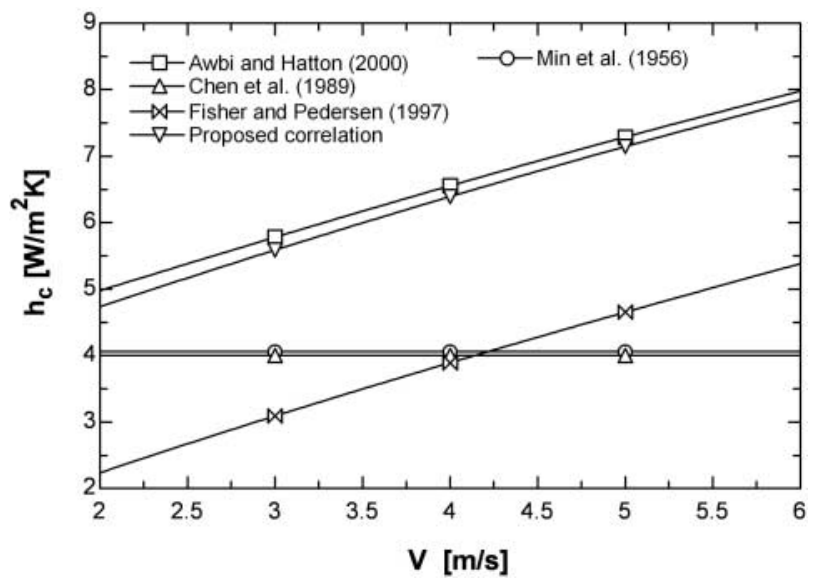

Figure 3. Mixed Convection Heat Transfer Coefficients for Various $V$ $\left(\Delta \mathrm{T}=8^{\circ} \mathrm{C}, D_{e}=3 \mathrm{~m}, V=0.5 \mathrm{~m}\right)$ 


$$
F_{R}=\frac{M C_{p}\left(T_{f o}-T_{f i}\right)}{A_{p} U_{o}\left(T_{a}-T_{f i}\right)}
$$

This analytical CRCP model requires knowledge of the overall heat transfer coefficient $\left(U_{o}\right)$. However, determination of $U_{o}$ is not achieved explicitly since the space temperature $\left(T_{a}\right)$ is generally not the same temperature as the area-weighted average temperature (AUST) of the surfaces exposed to the CRCPs. In principle, the total heat flux $\left(q_{o}\right)$ is the summation of the convective heat flux $\left(q_{c}\right)$ and the radiation flux $\left(q_{r}\right)$, as shown in Equation $7 \mathrm{a}$, and each heat flux can be expressed as Equation $7 \mathrm{~b}$ and $7 \mathrm{c}$, respectively.

$$
\begin{gathered}
q_{o}=q_{c}+q_{r} \\
q_{c}=h_{c} \cdot\left(T_{a}-T_{p m}\right) \\
q_{r}=h_{r} \cdot\left(A U S T-T_{p m}\right)
\end{gathered}
$$

$U_{o}$ can be easily determined by summing the convective heat transfer coefficient $\left(h_{c}\right)$ and the radiant heat transfer coefficient $\left(h_{r}\right)$, assuming $T_{a}=$ AUST; however, that assumption is generally not true. Therefore, in this work, the equivalent overall heat transfer coefficient $\left(U_{e}\right)$ has been defined as follows:

$$
U_{e}=\frac{q_{o}}{\left(T_{a}-T_{p m}\right)}
$$

By substituting Equation 7 into Equation 8, the final form of $U_{e}$ becomes

$$
U_{e}=\frac{q_{c}+q_{r}}{\left(T_{a}-T_{p m}\right)}=h_{c}+h_{r} \cdot \frac{\left(A U S T-T_{p m}\right)}{\left(T_{a}-T_{p m}\right)} .
$$

The radiant heat transfer coefficient (Equation 10) found in the literature (ASHRAE 2000) is

$$
h_{r}=5 \times 10^{-8} \cdot\left[(A U S T+273)^{2}+\left(T_{p m}+273\right)^{2}\right] \cdot\left[(A U S T+273)+\left(T_{p m}+273\right)\right] .
$$

The approximate expression for AUST (Kilkis et al. 1994) was used in this study.

$$
\begin{gathered}
\text { AUST } \approx T_{a}-d \cdot z \\
z \cong \frac{7}{\left(T_{o a}-45\right)} \text { when } 26^{\circ} \mathrm{C} \leq T_{o a} \leq 36^{\circ} \mathrm{C},
\end{gathered}
$$

where

$d=$ room position index with values as noted below:

0.5 for an interior space,

1.0 for a room with one outdoor exposed side with fenestration less than $5 \%$ of the total room surface area or

2.0 for a room with fenestration greater than $5 \%$, and

3.0 for a room with two or more outdoor exposed sides.

The equivalent overall heat transfer coefficient $\left(U_{e}\right)$ defined in Equation 9 can be used in place of the overall heat transfer coefficient $\left(U_{o}\right)$ in the panel model; however, $U_{e}$ cannot be 


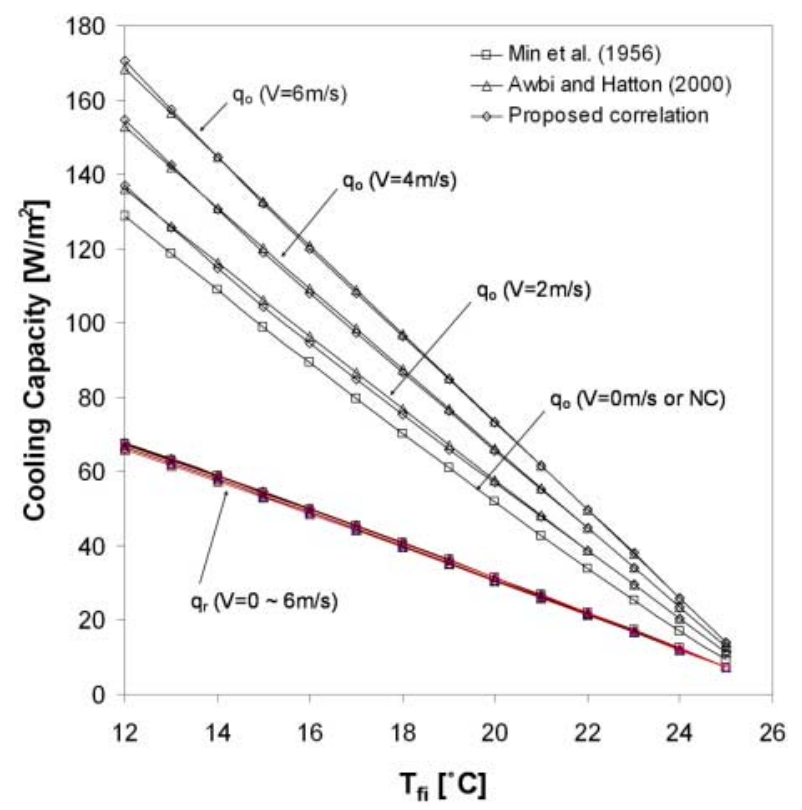

Figure 4. Total Cooling Capacity and Radiation Heat Flux

determined explicitly because the mean panel surface temperature $\left(T_{p m}\right)$ is unknown. This unknown $T_{p m}$ can be determined by solving the panel model equations (Equations 4 through 7) and Equation 9 for given boundary conditions iteratively. Once $U_{e}$ and $T_{p m}$ have converged, other quantities, such as the panel cooling capacities $\left(q_{o}, q_{c}\right.$, and $\left.q_{r}\right)$ and heat transfer coefficients $\left(h_{c}\right.$ and $\left.h_{r}\right)$ can be determined.

\section{CONVECTIVE AND RADIATIVE HEAT FLUX}

The total cooling capacity of the CRCP, when placed in the space illustrated in Figure 1, is presented in Figure 4. The panel heat transfer is strongly a function of air velocity due to the increasing convective heat transfer. As may be noted, the radiative heat transfer is essentially insensitive to the air velocity since the panels operate with a very small water temperature rise, or a nearly constant surface temperature.

The convective heat fluxes calculated with the simplified correlation and Awbi and Hatton's correlation closely agree.

The rate of total cooling enhancement by considering the mixed convection effect is presented in Figure 5. It shows that the total cooling capacity of a radiant panel can be enhanced dramatically by air motion.

\section{CONCLUSIONS}

Panel cooling capacity is enhanced significantly when mixed convection is considered. However, when the diffuser discharge air velocity is less than $2 \mathrm{~m} / \mathrm{s}$, the impact of mixed convection on the panel cooling capacity is small. Therefore, the correlation for the natural convection heat transfer coefficient can be used to estimate panel cooling capacity instead of the mixed convection correlation for low velocities. 


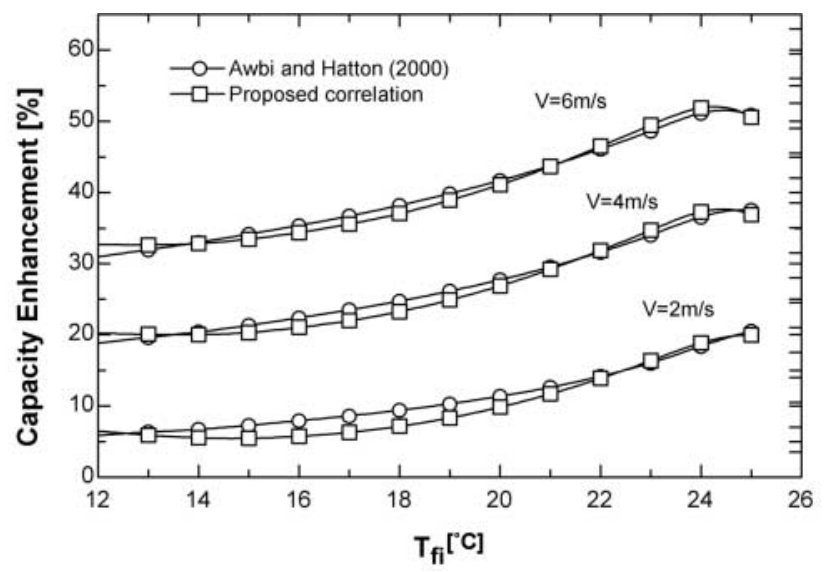

Figure 5. Panel Cooling Capacity Enhancement

The cooling panel capacity, when considering mixed convection, is enhanced $5 \%$ to $35 \%$ when the panel surface temperature is at typical design temperature. Consequently, engineers have been underestimating the panel cooling capacity in mechanically ventilated spaces by from $5 \%$ to $35 \%$. Better design tools are expected to reduce the required panel area and initial cost.

\section{ACKNOWLEDGMENT}

Financial assistance from ASHRAE's Grant-In-Aid program is greatly appreciated.

\section{NOMENCLATURE}

$A_{p}=$ panel area, $\mathrm{m}^{2}$

$C_{p} \quad=$ specific heat of the fluid, $\mathrm{kJ} / \mathrm{kg} \cdot \mathrm{K}$

$D_{e} \quad=$ characteristic diameter of room surface $(4$ $A_{c}(P), \mathrm{m}$

$F_{r} \quad=$ panel heat removal factor

$h_{c}=$ mixed convection coefficient, $\mathrm{W} / \mathrm{m}^{2} \cdot \mathrm{K}$

$h_{c f}=$ forced convection coefficient, $\mathrm{W} / \mathrm{m}^{2} \cdot \mathrm{K}$

$h_{c n}=$ natural convection coefficient, $\mathrm{W} / \mathrm{m}^{2} \cdot \mathrm{K}$

$h_{r} \quad=$ radiant heat transfer coefficient, $\mathrm{W} / \mathrm{m}^{2} \cdot \mathrm{K}$

$M \quad=$ mass flow rate to the panel, $\mathrm{kg} / \mathrm{s}$

$P \quad=$ parameter of the room, $\mathrm{m}$

$q_{c}=$ convective heat flux to the panel, $\mathrm{W} / \mathrm{m}^{2}$

$q_{r} \quad=$ radiant heat flux to the panel, $\mathrm{W} / \mathrm{m}^{2}$ $q_{o}=$ total sensible heat flux to the panel, $\mathrm{W} / \mathrm{m}^{2}$

$T_{a}=$ room air temperature, ${ }^{\circ} \mathrm{C}$

$T_{f i}=$ panel inlet fluid temperature, ${ }^{\circ} \mathrm{C}$

$T_{f o} \quad=$ panel outlet fluid temperature, ${ }^{\circ} \mathrm{C}$

$T_{p m}=$ mean panel surface temperature, ${ }^{\circ} \mathrm{C}$

$\Delta T=$ temperature difference between the space and the panel mean surface temperature, ${ }^{\circ} \mathrm{C}$

$U_{o} \quad=$ overall heat transfer coefficient, $\mathrm{W} / \mathrm{m}^{2} \cdot \mathrm{K}$

$U_{e} \quad=$ equivalent overall heat transfer coefficient, $\mathrm{W} / \mathrm{m}^{2} \cdot \mathrm{K}$

$\mathrm{V}=$ diffuser discharge air velocity, $\mathrm{m} / \mathrm{s}$

$W \quad=$ width of nozzle diffuser, $\mathrm{m}$

\section{REFERENCES}

ASHRAE. 2000. 2000 ASHRAE Handbook-HVAC Systems and Equipment. Atlanta: American Society of Heating, Refrigerating and Air-Conditioning Engineers, Inc.

Awbi, H.B., and A. Hatton. 1999. Natural convection from heated room surfaces. Energy and Buildings 30:233-244.

Awbi, H.B., and A. Hatton. 2000. Mixed convection from heated room surfaces. Energy and Buildings 32:153-166.

Chen, Q., C. Meyers, and J.V.D.R. Kooi. 1989. Convective heat transfer in rooms with mixed convection. International Seminar on Indoor Air Flow Patterns in Ventilated Spaces, Feb. 1989, Liege, Belgium, pp. 69-82. 
Conroy, C.L., and S.A. Mumma. 2001. Ceiling radiant cooling panels as a viable distributed parallel sensible cooling technology integrated with dedicated outdoor air systems. ASHRAE Transactions 107(1): 578-585.

DIN. 1997. DIN 4715, Cooling surfaces for rooms; Part 1: Measuring of the performance with free flow. Deutsches Institut fur Normung.

Fisher, D.E., and C.O. Pedersen. 1997. Convective heat transfer in building energy and thermal load calculations. ASHRAE Transactions 103(2): 137-148.

Hottel, H.C., and A. Whillier. 1958. Evaluation of flat-plate collector performance. Trans. of the Conference on the Use of Solar Energy 2(1): 74. University of Arizona Press.

Kilkis, B.I., S.S. Sager, and M. Uludag. 1994. A simplified model for radiant heating and cooling panels. Simulation Practice and Theory 2(2): 61-76.

Kochendörfer, C. 1996. Standard testing of cooling panels and their use in system planning. ASHRAE Transactions 102(1): 651-658.

Min, T.C., L.F. Schutrum, G.V. Parmelee, and J.D. Vouris. 1956. Natural convection and radiation in a panel heated room. Heating Piping and Air Conditioning (HPAC) May: 153-160. 
